\title{
Inside Information Leakage and Supervision in Private Placements
}

\author{
Xin SONG* and Zhi-Yuan FAN
}

\author{
Business School, University of Shanghai for Science and Technology, P.R.China \\ silvia_sx@163.com \\ ${ }^{*}$ Corresponding author
}

\begin{abstract}
Keywords: insider trading, private placement, regulatory measures
Abstract. Insider information disclosure exists in the trading of capital markets. The private placement of subscribers to manipulate stock prices through insider trading has seriously damaged the interests of small and medium investors, hindered the effective allocation of market resources, and hindered the development of China's capital market. However, the inside information leakage is subjective, the illegal cost is low, and it is difficult to obtain evidence to present a serious challenge to the supervision. This paper analyzes the situation and influence of inside information leakage in China's private placement, and puts forward the prevention measures for inside information leakage in private placement, which is of great significance to improve the legal policy supervision system of China's securities market.
\end{abstract}

\section{Introduction}

Private placement is a means of refinancing equity in listed companies, issuing investment products such as bonds or stocks to institutions or individual investors of no more than 10. Private placement is also known as "directed recruitment" or "relative to public offerings". Since the split share structure reform, the private placement has been favored by listed companies with its low financing threshold and cost advantage. However, because the major shareholder has a unique feature, it has a greater impact on the stock market than other investors. Therefore, once the major shareholder is based on the stock price manipulation of the information, it has damaged the interests of small and medium investors and seriously affected the healthy operation of the securities market. Domestic and foreign scholars analyze the data on the private placement of listed companies, and explain the destructiveness of inside information leakage to the open and fair securities market, and prove the universality of insider trading market behavior in private placements (Bhattacharya, 2009[5]; Xie Lin, 2011[22]).

Insider trading is defined as the act of an insider (usually an insider) who proceeds from investing in inside information with the help of his or her position (Bainbrige, 2000[2]). The main means of profit-making is to pay the lower consideration to reach the interests of the diluted minority shareholders, and realize the transfer of benefits while ensuring that their rights are not diluted (La Porta et al., 2000[10]). Insider trading not only increases market unfairness, but also harms the interests of unsuspecting people (Durnev, 2005[8]), and reduced the enthusiasm of small and medium investors in the stock market, thus reducing market liquidity (Bhattacharya, 2009[5]).

In 2014, China World Bank's directional private information disclosure incident was a sensation. During the first 20 days after the release of the revised version of the World Bank's private placement, the World Bank had a daily limit of one day and was suspended for the next day. The reason is that the shareholder Yang Chenglu, as the special assistant to the chairman, learned and leaked the inside information. His relatives and friends opened the position ahead of time and bought a large number of stocks at a low price, which seriously undermined the fairness of the market. Insider traders in private placements are highly concealed, illegal evidence collection is difficult, and there are insiders who exclude supervision. The insider trading behavior in the private placement after the issuance of relevant policies is still repeated. How to take effective supervision measures to curb its insider trading has become a top priority.

Inhibition of insider trading measures include legal sanctions and trading controls. The former prevents insider trading by raising the cost of illegal activities. The Securities Exchange Law (1934) 
promulgated by the United States and the Securities Law (1999) promulgated by China strictly prohibit the conduct and punishment of insider trading. The latter use the improvement of the information transmission and disclosure system, to make the implementation of the entire process of control. Improve the transparency of information, reduce the degree of information asymmetry, and avoid the use of insider information.

From the above analysis, the most recent measure to curb insider trading is the ex-post punishment of insider trading. After research, it is known that personal psychological factors will affect insider trading in the process, so stronger punishment can restrain insider trading (Beams, 2002[6]).

But La porta et al (2006) [10] believed that law enforcement agencies have no effect on the after-the-fact punishment of insider trading. Obviously, there is only limited effectiveness in dealing with insider trading, and it is necessary to reasonably analyze the motives of insider trading behavior and establish an analysis module (Li Xindan et al.2007[25]), adopting data mining methods to dynamically screen insider trading (Zhang Zongxin, 2008 [18]) and other pre-determination and prevention.

Through the above literature review and related current events, we can see that the current research on inside information leakage mainly focuses on all aspects of insider trading and the harm of the insider trading to the securities market. However, there is no specific effective measure for how to monitor the inside information leakage of private placement and how to effectively curb insider trading in private placement. This paper analyzes the problem of insider information leakage from the perspective of the impact of the disclosure of inside information leakage and how to ensure the effectiveness of inside information leakage in the private placement, and proposes improvement suggestions.

\section{Inside Information Leakage in Private Placements}

\subsection{The Connotation of Insider Trading and Insider Information}

Insider trading is the "substantial non-public information" that the general insider has mastered. Finding the right time to invest in securities and gain personal profits (Bainbrige, 2000[2]). Article 69 of China's Securities Law states that insider information has two characteristics, one is undisclosed, and the other is that it has a significant impact on market prices. Because insider information has a significant impact, once it leaks, it will cause irreversible damage to the securities market. In essence, insider trading is a proxy problem. Since private placement involves listed companies, securities companies, etc., the number of insider personnel is very large. As a result, the agency problem will be more serious (Gu Yongli, 2003[12]).

The insider information is generated essentially because if a listed company discloses all information to investors, it will damage trade secrets and affect normal business transactions (Zhu Hongmei, 2002[27]). Trade secrets of great value are used by private individuals to participate in private placements and become a tool for them to earn revenue.

\subsection{Directed Issuance of Inside Information Leakage and Impact}

Foreign scholars believe that there are three types of stock price manipulation. The first category is stock price manipulation based on inside information, and the second is behavior manipulation. Classes are manipulated through transactions (Allen \& Gale, 1992[1]). Behavior manipulation and trading manipulation are the direct manipulation of the stock market by shareholders. Directed issuance of insider trading market is an information-based stock price manipulation, which poses a huge challenge to regulators due to its great concealment. In the private placement, the insider colludes with an external institutional investor or an individual who has an interest relationship with the insider in exchange for huge amounts of income by knowing inside information in advance. The stock option equity incentive system and the management shareholding (MBO) are becoming more and more common in the private placement of insider information through insider information. The complexity of the people involved and the concealment of information transmission channels have 
made it difficult for supervision, and it has also made the private placement of insider trading one of the main ways for information acquirers to make profits.

In the discussion on the impact of private placements on insider trading, some scholars initially proposed the "inside compensation theory".It is believed that the appropriate compensation for insiders of the company can be obtained from insider trading, and insider trading can compensate the agency cost of the company (Carlton \& Fischel, 1983[7]).Insider trading can be reflected at the price level, corporate value is well reflected, and market interest rates can be improved steadily (Leland, 1992[9]; Spencer, 2000[11]).

Most scholars today oppose the above-mentioned arguments and suggest that insider information leaks more harm than good. Insider information disclosure allows internal traders to manipulate stock prices using insider information (He Jia \& He Jibao, 2001[13]).In the market of private placements, due to prior knowledge of corporate restructuring, mergers and other major issues, or to notify others to buy and sell company stocks and other insider trading, the original equity has not been diluted, but information-based stock price manipulation has been formed, and the destruction is extremely great, resulting in the loss of the interests of most small and medium shareholders.

Xie Lin (2010[21]) found that there was a serious stock price manipulation on the day before the private placement by analyzing the relevant data on the day before the announcement of the private placement plan. And insider trading has weakened capital market efficiency through serious stock price manipulation (Shi Yongdong \& Jiang Xianfeng, 2003[14]).If the insider trading of the private placement is exposed, the psychological score of the listed company will be reduced, which will lead to fewer people choosing the company to issue additional shares or even abandon the private placement, which has hit the enthusiasm of small and medium shareholders to participate in the market (Bhattacharya, 2009[5]).

\subsection{Trading Supervision in Private Placements}

The transaction supervision measures for private placement are mainly divided into ex-post punishment measures based on legal supervision and improvement of information disclosure systems and other pre-regulation and prevention measures. A number of countries have introduced legal policies related to insider trading. The implementation of the Insider Trading Act can significantly reduce the company's equity costs (Bhattacharya, 2002[4]), and the shareholding structure is more dispersed, asset prices are more reasonable, and market liquidity is better (Beny, 2007[3]).

The rigor of the regulatory environment is negatively correlated with the extent of information leakage (Wang Yihao, 2008)[17].In real life, after the introduction of the corresponding laws, the effectiveness of the supervision of insider trading has been improved (Jing Yushen, 2014[24]).In China, directional issuance of insider trading generally takes the form of civil penalties. In the standard of civil punishment, the amount of fines is 1 to 5 times of the illegal income, and the amount of fines is 600,000 yuan when there is no illegal income. It does not have a good supervision effect on large-value transactions, and the illegal benefits are still greater than illegal cost. In the current securities law, the definition of insider trading and its personnel is still not clear and specific, and the identification of insider trading entities is not complete (Li Shouxi \&Tang Yuanping, 2017[19]).

But the law has certain limitations. Due to the difficulty in investigating and proving the insider trading, the lack of law enforcement, and the time lag in law enforcement efficiency, the illegal cost of false information disclosure and insider traders was lower than the illegal income (Wang Chunfeng et al, 2003[15]) found that the effectiveness of insider trading supervision is still insufficient by comparing the changes in stock price information before and after the implementation of relevant laws in various countries, especially in developing countries. Therefore, due to the subsequent punishment of legislation and other measures, it is still impossible to eliminate the situation of insider trading in private placements, which makes extra-priorlative supervision and prevention in the event become extraordinarily important. The improvement of the information disclosure system and other pre-regulatory and anti-initiative measures have become the regulatory measures for making up for the lack of legality. Due to the degree of information asymmetry is the main reason for insider trading. Therefore, ensuring a reasonable information disclosure system beforehand can reduce the degree of 
asymmetry, so that it can effectively monitor insider trading beforehand (Shi Yongdong \&Jiang Xianfeng, 2003[14]). At the same time, an ex-ante reporting system for insider trading should be established. This system can ensure that the behavior of insider purchases and sales is under effective supervision, which can effectively reduce speculation in the process of private placement (Li Yong, 2003[23]). In addition to ex ante regulation and stop-action, it is also important to apply positive incentives. From a psychological point of view, the insider information disclosure is not entirely tempted by interest. The influence of psychological factors such as vanity and herding on the insider trading in Dingzeng exists (Li Guangshuai, 2017[20]). Insider trading prevention and control should also pursue efficiency, only effective when the efficiency of insider trading is brought to the market is higher than the cost. (Zhu Weihua, 2007[16]). Therefore, the establishment of anti-control (the pre-regulation, the suppression of the matter, and the punishment afterwards) on the private placement of insider trading should also pay attention to the cost of prevention and control.

In summary, we should not only focus on the after-the-fact punishment of insider trading in private placements, but should further deepen the reform, reduce the approval, improve the timeliness of information disclosure of listed companies, make the company's information disclosure more perfect, and maintain the private placement is always in the regulatory environment. At the same time, in the rapid development of science and technology, the hidden private placement of insider trading is more difficult to supervise. We should establish more effective insider trading identification mechanisms, conduct effective pre-regulation and stop things, and gradually realize data sharing to maintain the securities market fair and open.

\section{Conclusion}

This paper analyzes the negative impact of insider trading in private placements and the measures that should be taken to strengthen supervision. As a widely respected refinancing method, private placement is favored by investors. However, in terms of the efficiency and fairness of capital market financing, there are indeed many problems in private placement. Directional issuance Insider trading has infringed the interests of small and medium shareholders, and large shareholders have enjoyed huge profits from the opportunity to issue, which has aggravated the information asymmetry in the market, hindered the healthy development of the securities market and affected the efficiency of the capital market. The securities regulatory department is difficult to supervise because of its hidden and complex characteristics.

We will learn from the supervision of insider trading and improve the regulatory measures for insider trading in private placements. First, improve relevant laws and clarify the responsibilities of the law of the offender. Secondly, under the premise of perfecting the law, establish relevant systems for pre-existing monitoring and deterrence. Construct an effective insider trading identification structure to identify insider trading behaviors in private placement and establish relevant incentive mechanisms. Try to prevent insider trading from the beginning, prevent precautions, stop things, punish and motivate afterwards. To conduct more effective supervision to ensure the steady development of the securities market and reduce the invasion of rights by major shareholders. In addition, an effective incentive and guidance mechanism should be established to minimize the probability of insider trading by insiders who are exposed to external interests and their own psychological factors.

Today, with the rapid development of science and technology, insider trading has become more and more concealed. Therefore, in the future, the legal system will be improved, the inside information disclosure system and regulatory measures will be refined, the wall system will be improved, an effective pre-existing identification mechanism and a positive incentive mechanism will be established. It is the most important task in resolving the regulation of insider trading in private placement, protecting the interests of market investors and maintaining the order of the securities market. 


\section{References}

[1] F.Allen, D. Gale.Stock-Price Manipulation[J]. The Review of Financial Studies, 1992.

[2] S.M. Bainbridge, Insider Trading: An Overview. 43(1998):29.

[3] L.N. Beny, L. Nyantung. Insider Trading Laws and Stock Markets Around the World: An Empirical Contribution to the Theoretical Law and Economics Debate[J]. Journal of Corporation Law, 2007, 32(2).

[4] U. Bhattacharya, H.Daouk. The World Price of Insider Trading[J]. The Journal of Finance, 2002, 57(1):75-108.

[5] U. Bhattacharya, H.Daouk. When No Law is Better Than a Good Law[J]. Review of Finance, 2009, 13(4):577-627.

[6] J.D. Beams. Insider Trading: A Study of Motivations and Deterrents[J]. The Virginia Polytechnic Institute and State University,2002.

[7] D.Canton, D.Fischel. The Regulation of Insider Trading[J]. Stanford Law Review. Journal of Law and Economics, 1987(30):311-352

[8] A.A.Durnev, A.S. Nain. The Effectiveness of Insider Trading Regulation Around the Governance Journal of Financial Economics[Z]. Working paper, University of Miami,2005(58):3-27.

[9] H. E. Leland. Insider Trading: Should It Be Prohibited? [J]. Journal of Political Economy, 1992, 100(4):859-887.

[10] R. L. Porta, F. Lopez-De-Silane, A. Shleifer. What Works in Securities Law? [J]. The Journal of Finance, 2003, 61(1):1-32.

[11] J.P. Spencer. The Structure and Regulation of Financial Markets[J]. Economic Journal, 2002, 112(477).

[12] Y.L. Gu. Research on the role of insider trading regulation on company value[D]. Shanghai: Fudan University, 2003.

[13] J. He, J.B.He. Information disclosure of major events in China's stock market and stock price changes[R]. Shenzhen: Research Report of the Comprehensive Research Institute of Shenzhen Stock Exchange, 2001.

[14] Y.D. Shi, X. F. Jiang. Adjustment of stamp duty in China's securities market Effect Analysis [J]. World Economy, 2003 (12): 63-71.

[15] C.F. Wang, X. L. Jiang, D. Han. Insider Trading and Supervision of China's Stock Market: International Experience and China's Countermeasures [J]. International Finance Research, 2003(03)

[16] W.H. Zhu. Research on Insider Trading Supervision and Supervision Dilemma Review [J]. Securities Market Herald, 2007 (09): 33-37.

[17] Y.H. Wang. Regulatory environment, equity characteristics and information disclosure [D]. Fudan University, 2008.

[18] Z.X. Zhang. Insider Trading Behavior Prediction: Theoretical Model and Empirical Analysis [J]. Management World, 2008(04): 24-35.

[19] S.X. Li, Y.P. Tang. Characteristics and Supervision Defects of Insider Trading Cases in China -Based on the Enforcement Cases from 1998 to 2016[J]. Journal of Shanghai University (Social Science Edition)

[20] G.S. Li. Analysis of the causes of internal information leakage in China's securities market and its regulatory countermeasures [D]. Beijing Jiaotong University, 2017. 
[21] L. Xie, S.L. Tang, Y.M. Yin. Insider trading, stock price manipulation and the effect of large shareholder encroachment:based on the full-circulation era of private placement[J].Science and Technology Management Research(3):247-253.

[22] L. Xie. Private placement of listed companies and stock returns[D]. Shanghai Jiaotong University, 2011

[23] Y. Li. Research on Information Disclosure Model of "Internal Person" Transactions in China's Securities Market[D]. Xiamen University, 2003.

[24] Y.S. Jing. Research on the Effectiveness of Insider Trading Supervision and Market Response in China's Securities Market[D]. Shanghai Traffic University, 2014.

[25] X.D. Li, Y.C. Liu,Y.N. Wang. Characteristics of Refinancing Behavior of Listed Companies[J]. Investment Research, 2007(01): 46-48.

[26] G.X. Wang. Empirical Study on the Market Effect of Privately-issued Listed Companies [D]. Southwestern University of Finance and Economics, 2013.

[27] H.M. Zhu. Insider information, insider trading and Its regulation [J]. Nankai Economic Research, 2002 (02): 16-20. 